\title{
CRESCIMENTO DE MUDAS DE MAMOEIRO 'FORMOSA' EM SUBSTRATOS COM UTILIZAÇÃO DE COMPOSTO ORGÂNICO E SUPERFOSFATO SIMPLES ${ }^{1}$
}

\author{
Growing of papaya 'Formosa' plants in substrates within organic \\ compost and simple superphosphate
}

\author{
Vander Mendonça ${ }^{2}$, Nildo Antônio Arruda de Abreu ${ }^{3}$, Rafael Lucas da Silva Gurgel ${ }^{4}$, \\ Ester Alice Ferreira ${ }^{5}$, Maria Yumbla Orbes ${ }^{4}$, Mauro da Silva Tosta ${ }^{6}$
}

\begin{abstract}
RESUMO
Este trabalho foi conduzido em viveiro de formação de mudas no Campus da Universidade Federal de Lavras (UFLA), Minas Gerais, com o objetivo de avaliar diferentes doses de composto orgânico e de superfosfato simples na produção de mudas de mamoeiro 'Formosa'. Foram testadas num Latossolo Vermelho distrófico, quatro doses de superfosfato simples 0,0; 2,5; 5,0 e 10,0

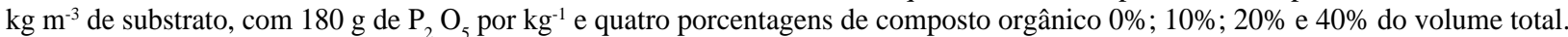
$\mathrm{O}$ delineamento experimental utilizado foi blocos ao acaso em esquema fatorial 4 x 4, com 4 repetições e cinco plantas por parcela. Foram realizadas as seguintes determinações: altura de plantas $(\mathrm{cm})$; comprimento da raiz $(\mathrm{cm})$, número de folha/planta, matéria seca da parte aérea, da raiz e total (g/planta). Os resultados demonstraram que a utilização do superfosfato simples na dose de $10 \mathrm{~kg} \mathrm{~m}^{-3}$ em substrato para formação da muda garante melhor qualidade na formação de mudas de mamoeiro 'Formosa'. O composto orgânico em percentuais de $40 \%$ no substrato mostrou ser uma alternativa de matéria orgânica viável, para formação de mudas de mamoeiro.
\end{abstract}

Termos para indexação: Carica papaya L., propagação, adubação orgânica e fosfatada.

\begin{abstract}
This work was carried out in a greenhouse of plant formation at Campus of Universidade Federal de Lavras, UFLA, Minas Gerais aiming to evaluate different doses of organic compost and simple super phosphate in papaya 'Formosa' seedling. It was tested

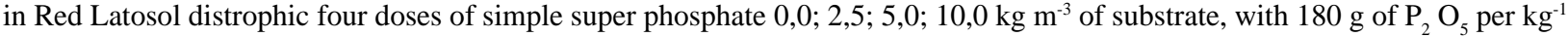
and four percentages of organic compost $0 \%, 10 \%, 20 \%$, and $40 \%$ of total volume. A randomized block design was used with factorial scheme $4 \times 4$, with four replications and five plants by plot. It was evaluate the following characteristics: high of plants (cm), root length $(\mathrm{cm})$ number of leaves/plants, dry matter of aerial part and root $(\mathrm{g} / \mathrm{plant})$. The results showed that the use of simple super phosphate at $10 \mathrm{~kg} \mathrm{~m}^{-3}$ in substrates warranty best quality in plant formation of papaya Formosa. The organic compost at $40 \%$ in substrates showed is a viable alternative in organic matter for plant formation of papaya.
\end{abstract}

Index terms: Carica papaya L., propagation, organic and phosphate fertilization.

(Recebido para publicação em 29 de agosto de 2005 e aprovado em 5 de julho de 2006)

\section{INTRODUÇÃO}

A cultura do mamoeiro vem se expandido com perspectivas favoráveis, uma vez que o fruto é bem aceito no mercado consumidor. Sua importância deve-se, principalmente, ao grande aproveitamento dos frutos que são consumidos in natura, e na fabricação de doces, na extração de papaína e produtos cosméticos. No Brasil, as regiões sudeste e nordeste somam em média $87,5 \%$ da produção nacional, destacando-se os estados do Espírito Santo e Bahia como os principais produtores. O Brasil em 2001 produziu 1.489.324 toneladas em uma área cultivada de 37.299 ha (AGRIANUAL, 2004).

Apesar da grande importância da cultura do mamoeiro na fruticultura nacional, de modo geral, poucas pesquisas têm sido desenvolvidas com essa frutífera, principalmente em relação à formação de mudas (MENDONÇA et al., 2003).

$\mathrm{Na}$ composição do substrato para a produção de mudas de mamoeiro existe a recomendação do uso de adubação orgânica, a qual traz como vantagens a melhoria das condições físicas, químicas e biológicas do solo (OLIVEIRA et al., 1994). Para Trindade (2000), o aperfeiçoamento das técnicas de produção de mudas de mamoeiro é de extrema importância, já que o crescimento inicial das mudas tem relação direta com a precocidade e produção de frutos.

$\mathrm{O}$ fornecimento adequado de $\mathrm{P}$ às mudas proporciona excelentes respostas, tanto a nível radicular como da parte aérea. Um substrato deficiente de $\mathrm{P}$ ocasiona

\footnotetext{
${ }^{1}$ Trabalho financiando com bolsa da CAPES e CNPq.

2Engenheiro Agrônomo, Dr. Professor Adjunto da Universidade Estadual de Mato Grosso do Sul/UEMS - Rod. MS 306 , Km 6 - $79.540-000$ Cassilândia, MS - vanderm@uems.br

${ }^{3}$ Engenheiro Agrônomo, M.Sc. Departamento de Agricultura da Universidade Federal de Lavras/UFLA - Cx. P. 3037 - $37200-000$ - Lavras, MG. ${ }^{4}$ Graduandos em Agronomia pela Universidade Federal de Lavras/UFLA - Cx. P. 3037 - 37200-000 - Lavras, MG.

${ }^{5}$ Engenheira. Agrônoma, M.Sc. Doutorando em Agronomia/UFLA - Cx. P. 3037 - 37200-000 - Lavras, MG - ester@ufla.br.

${ }^{6}$ Graduando pela Universidade Estadual de Mato Grosso de Sul/UEMS - Rod. MS 306, Km 6 - 79.540-000 - Cassilândia, MS
} 
um crescimento reduzido ou menor das raízes e da parte aérea, sendo necessária a suplementação com fertilizantes fosfatados nos substratos com deficiência (YEAGER \& WRIGHT, 1984).

O uso do superfosfato simples é preferível no fornecimento de fósforo $\left(\mathrm{P}_{2} \mathrm{O}_{5}\right.$ sol. em CNA $\left.+\mathrm{H}_{2} \mathrm{O}\right)$, pois contém cálcio (25-28\% CaO) e enxofre (12\%), e a aplicação de $1,2 \mathrm{~kg} / \mathrm{m}^{2}$ desse fertilizante eleva em $5 \mathrm{mg} \mathrm{L}^{-1}$ o teor desse nutriente no extrato saturado (CARMELLO, 1995). Em meios pobres em fósforo a aplicação de 1,2 a 1,8 $\mathrm{kg} \mathrm{m}^{-}$ ${ }^{2}$ de substrato fornece quantidades adequadas de fósforo para o crescimento da muda (CARMELLO, 1995).

Algumas pesquisas com utilização de adubação fosfatada e/ou orgânica na formação de mudas de mamoeiro tem apresentado bons resultados, demostrando a importância destes componentes na formação do substrato para produção da muda do mamoeiro (FERNANDES et al., 2002; LIMA, 1996; PONTES, 1991; OLIVEIRA et al., 2002; ROCHA, 1987).

Objetivou-se neste trabalho avaliar o efeito do composto orgânico e da adubação com superfosfato simples na formação de mudas de mamoeiro 'Formosa'.

\section{MATERIAL E MÉTODOS}

O experimento foi conduzido em viveiro de formação de mudas, no Campus da Universidade Federal de Lavras (UFLA), Minas Gerais, cercado com telado de nylon tipo sombrite, permitindo $50 \%$ de luminosidade no seu interior e uma boa ventilação.
As mudas utilizadas nesta pesquisa foram obtidas de sementes da empresa ISLA PAK ${ }^{\hat{a}}$ sendo utilizada a cultivar Formosa com $71 \%$ de germinação e $99,9 \%$ de pureza, conforme dados do fabricante.

Como substrato, utilizou-se solo classificado como Latossolo Vermelho distrófico, coletado na camada de 0$20 \mathrm{~cm}$ de profundidade, no campus da UFLA, cujo resultado da análise química encontra-se nos Tabelas 1 e 2 .

As sementes foram semeadas em sacos plásticos $(10 \times 20 \mathrm{~cm})$ furados lateralmente, com capacidade para 0,5 $\mathrm{kg}$ de solo. Foram utilizadas duas sementes por recipiente e após a germinação quando as mudas atingiram $5 \mathrm{~cm}$ foram desbastadas deixando-se a mais vigorosa.

A adubação do substrato foi realizada uma semana antes da semeadura, misturando-se ao substrato o composto orgânico nas quantidades de $0 ; 10 ; 20$ e $40 \%$ do volume do substrato e o superfosfato simples ( $180 \mathrm{~g}$ de $\mathrm{P}_{2}$ $\mathrm{O}_{5} \mathrm{~kg}^{-1}$, solúvel em água) nas doses de $0 ; 2,5 ; 5$ e $10 \mathrm{~kg}$ por metro cúbico de substrato.

Na formação do composto orgânico foram utilizadas palhada de feijão, palhada de milho, palha de arroz, casca de banana, casca de laranja, carvão vegetal e esterco bovino como componentes. $\mathrm{O}$ resultado da análise química do composto é mostrado nas Tabelas 1 e 2 .

Os tratos culturais utilizados foram a irrigação (de manhã e a tarde), controle de pragas e doenças e, a monda das plantas daninhas. A adubação de cobertura, via foliar, foi realizada quinzenalmente e repetida 3 vezes, sendo iniciada após o desbaste com aplicação de nitrogênio, na forma de uréia $(0,2 \%)$.

TABELA 1 - Resultados da análise físico-química do solo e do composto orgânico utilizados no experimento com mamoeiro 'Formosa', realizada pelo Laboratório de Fertilidade do Solo da UFLA'.

\begin{tabular}{|c|c|c|c|c|c|c|c|c|c|c|c|c|c|}
\hline Substrato & PH & $\mathbf{P}$ & $\mathbf{K}$ & $\mathbf{C a}$ & Mg & Al & $\mathbf{H}+\mathbf{A l}$ & SB & $\mathbf{t}$ & $\mathbf{T}$ & $\mathbf{V}$ & M.O & P-rem \\
\hline & $\mathbf{H}_{2} \mathbf{O}$ & \multicolumn{2}{|c|}{$\mathrm{mg} \mathrm{dm}^{-3}$} & \multicolumn{7}{|c|}{ 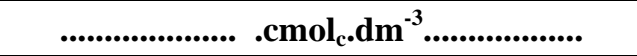 } & $(\%)$ & dag.kg ${ }^{-1}$ & $\mathrm{mg} \mathrm{L}^{-1}$ \\
\hline Solo & 5,5 & 0,9 & 14 & 1,8 & 0,5 & 0,0 & 2,3 & 2,3 & 2,3 & 4,6 & 50,4 & 1,2 & 6,0 \\
\hline Comp. & 6,7 & 329 & 301 & 16,2 & 5,3 & 0,0 & 1,3 & 22,3 & 22,3 & 23,6 & 94,5 & 6 & 43,4 \\
\hline
\end{tabular}

${ }^{1} \mathrm{SB}$ - soma de bases; t- CTC efetiva; T- CTC a pH 7,0; V - saturação de bases.

TABELA 2 - Resultados da análise de micronutrientes e do enxofre no solo e no composto orgânico no experimento com mamoeiro 'Formosa', realizada pelo Laboratório de Fertilidade do Solo da UFLA.

\begin{tabular}{ccccccc}
\hline Substrato & $\mathbf{Z n}$ & $\mathbf{F e}$ & $\mathbf{M n}$ & $\mathbf{C u}$ & $\mathbf{B}$ & $\mathbf{S}$ \\
\hline & & $\mathbf{m g ~ d m}^{-3}$ & & & \\
\hline Solo & 0,5 & 49,2 & 8,3 & 3,1 & 0,7 & 15,4 \\
Composto & 23,5 & 45,8 & 71,7 & 0,5 & 1,4 & 35,3 \\
\hline
\end{tabular}

Ciênc. agrotec., Lavras, v. 30, n. 5, p. 861-868, set./out., 2006 
O delineamento experimental utilizado foi em blocos casualizados, em esquema fatorial 4 x 4 . Os tratamentos foram constituídos pela combinação de 4 doses de superfosfato simples $(0 ; 2,5 ; 5$ e $10 \mathrm{~kg}$ por metro cúbico de substrato e 4 porcentagens de composto orgânico ( $0 ; 10$; 20 e $40 \%$ do volume total do substrato) com 4 repetições. Cada parcela foi constituída por 5 mudas, uma em cada recipiente .

As variáveis avaliadas, aos 140 dias após a semeadura, foram: altura de planta $(\mathrm{cm})$, medida a partir do colo da muda até a gema apical; comprimento da raiz $(\mathrm{cm})$, número de folha/planta. Posteriormente as partes foram colocadas em estufa à temperatura de $65^{\circ} \mathrm{C}$, até atingir peso constante. Após isso, foram efetuadas pesagens, encontrando-se assim a matéria seca da parte aérea e matéria seca da raiz e com a soma das duas encontrou-se a matéria seca total.

Os dados foram submetidos à análise de variância e para os dados quantitativos foi empregada a análise de regressão (GOMES, 2000). As análises foram realizadas pelo programa computacional Sistema para Análise de Variância - SISVAR (FERREIRA, 2000).

\section{RESULTADOS E DISCUSSÃO}

O resultado da análise físico-química do composto orgânico é apresentado nas Tabelas 1 e 2. Observam-se valores expressivos em relação a todos os nutrientes, principalmente em relação ao $\mathrm{P}, \mathrm{K}$ e $\mathrm{Ca}$ que são macronutrientes de grande importância para a cultura do mamoeiro, especialmente o P com influência na emissão e tamanho de folhas e do Ca que participa do crescimento e do desenvolvimento do sistema radicular (SIMÃO, 1998).

Pela análise de variância apresentada na Tabela 3 verificam-se os efeitos significativos pelo teste $\mathrm{F}(\mathrm{p}<0,01)$ para a interação das doses de superfosfato simples e do composto orgânico nas características altura, comprimento da raiz, matéria seca da parte aérea da raiz e total. Para o número de folhas houve efeito dos dois fatores isoladamente.

As mudas de mamoeiro apresentaram incremento linear positivo para a característica altura, à medida em que se aumentaram as doses do superfosfato simples, bem como a \% do composto orgânico no substrato, demostrando o efeito benéfico dos dois fatores no crescimento das mudas. Verificando a Figura 1 observase que, após 140 dias da semeadura, apenas na dose 10 $\mathrm{kg} \mathrm{m}^{-3}$ do superfosfato simples com $20 \%$ ou $40 \%$ do composto orgânico é que as mudas tiveram altura superior a $15 \mathrm{~cm}$, considerada por Soares (1998) como o tamanho ideal para que as mudas sejam levadas a campo. Rocha (1987) também obteve respostas positivas com a utilização do superfosfato simples e da matéria orgânica no crescimento de mudas de mamoeiro. Segundo este autor a adição de matéria orgânica e do superfosfato simples induziram o maior crescimento das mudas de mamoeiro, sendo que a matéria orgânica teve uma atuação mais efetiva quando comparada ao adubo fosfatado. De um modo geral, o melhor resultado obtido foi a interação $3 \mathrm{~kg}$ de superfosfato simples e 200 litros de matéria orgânica por metro cúbico de substrato.

TABELA 3 - Resumo da análise de variância da altura, comprimento da raiz, número de folhas, matéria seca da parte aérea, da raiz e total, em função de doses de superfosfato simples (SS) e da porcentagem de composto orgânico (CO), na produção de mudas de mamoeiro 'Formosa'. Lavras, MG, 2004.

\begin{tabular}{cccccccc}
\hline $\begin{array}{c}\text { Fontes de } \\
\text { Variação }\end{array}$ & GL & Altura $(\mathbf{c m})$ & $\begin{array}{c}\text { Comprimen } \\
\text { to da raiz } \\
(\mathbf{c m})\end{array}$ & $\begin{array}{l}\mathbf{N}^{\circ} \text {. de } \\
\text { folhas }\end{array}$ & $\begin{array}{c}\text { Matéria seca } \\
\text { da parte } \\
\text { aérea }(\mathbf{g})\end{array}$ & $\begin{array}{c}\text { Matéria seca } \\
\text { da raiz } \\
(\mathbf{g})\end{array}$ & $\begin{array}{c}\text { Matéria seca } \\
\text { total } \\
(\mathbf{g})\end{array}$ \\
\hline SS & 3 & $175,781993^{* *}$ & $122,55935^{* *}$ & $7,864368^{* *}$ & $3,853383^{* *}$ & $0,519045^{* *}$ & $7,290349^{* *}$ \\
CO & 3 & $114,589596^{* *}$ & $68,016235^{* *}$ & $12,46555^{* *}$ & $1,746063^{* *}$ & $0,442941^{* *}$ & $3,836923^{* *}$ \\
SS x CO & 9 & $4,467689^{* *}$ & $13,367652^{* *}$ & $1,245882 \mathrm{~ns}$ & $0,234491^{* *}$ & $0,034488^{* *}$ & $0,386202^{* *}$ \\
Bloco & 3 & $0,749506 \mathrm{~ns}$ & $1,868881^{* *}$ & $6,273452^{*}$ & $0,063445^{*}$ & $0,006338^{* *}$ & $0,062945^{* *}$ \\
Resíduo & 36 & 0,943579 & 0,146319 & 0,951941 & 0,040272 & 0,005442 & 0,058514 \\
\hline $\mathrm{CV}(\%)$ & & 9,36 & 2,36 & 12,27 & 27,56 & 22,39 & 22,76 \\
\hline
\end{tabular}

**Significativo a $1 \%$ de probabilidade, pelo teste F; *Significativo a $5 \%$ de probabilidade, pelo teste F. ns -Não-significativo. 
Para a variável comprimento da raiz com aplicação de $0 \%$ e $10 \%$ de composto e $10 \mathrm{~m}^{-3}$ do superfosfato simples os comprimentos foram equivalentes de 19,05 e 19,19 cm, respectivamente e com $20 \%$ de composto e $7,39 \mathrm{~kg} \mathrm{~m}^{-3} \mathrm{de}$ superfosfato simples obteve-se comprimento de $20,024 \mathrm{~cm}$. (Figura 2).

O número de folhas teve influência do superfostato simples e da \% de composto orgânico isoladamente. Em relação do superfostato simples (Figura 3) a melhor resposta $(8,86)$ foi obtida na dose $10 \mathrm{~kg} \mathrm{~m}^{-3}$. Já em relação a \% do composto orgânico (Figura 4) a melhor resposta $(8,99)$ foi quando se utilizou a $40 \%$.

A interação superfosfato simples e composto orgânico foi significativa também para a matéria seca da parte aérea, da raiz e total. As respostas para estas variáveis também seguiram um comportamento linear crescente com as melhores repostas $2,01 \mathrm{~g}, 0,89 \mathrm{~g} \mathrm{e} 2,90 \mathrm{~g}$ para a matéria seca da parte aérea (Figura 5), matéria seca da raiz (Figura 6) e matéria seca total (Figura 7), respectivamente obtidas na dose de $10 \mathrm{~kg} \mathrm{~m}^{-3}$ de superfosfato simples e $40 \%$ de composto orgânico. $\mathrm{O}$ ganho em matéria seca das mudas obtido na dose de $10 \mathrm{~kg} \mathrm{~m}^{-3}$ de superfosfato simples e $40 \%$ de composto orgânico foi mais de dez vezes superior ao obtido nos tratamentos sem utilização deste fertilizante e do composto orgânico. Estes resultados mostraram que, a adição do fertilizante e do composto orgânico ao substrato de formação das mudas de mamoeiro, induziram um maior crescimento das mesmas, sendo que o composto orgânico propiciou um maior efeito a partir do percentual de $20 \%$ no substrato e o superfosfato simples na maior dose.

Pontes (1991) observou que a adição de uma parte de esterco bovino e três partes de terra firme, na composição de substrato para produção de mudas de mamoeiro, apresentou efeitos benéficos para altura, comprimento das raízes, diâmetro do colo e peso da matéria seca das raízes, tanto na presença como na ausência de adubação química.

Lima (1996) encontrou efeito significativo da interação fontes de fósforo $\mathrm{x}$ esterco de curral; calcário $\mathrm{x}$ esterco de curral e da interação fontes de fósforo x calcário $\mathrm{x}$ esterco de curral e que o esterco de curral proporcionou os melhores resultados quando utilizado na composição do substrato para produção de mudas de mamoeiro.

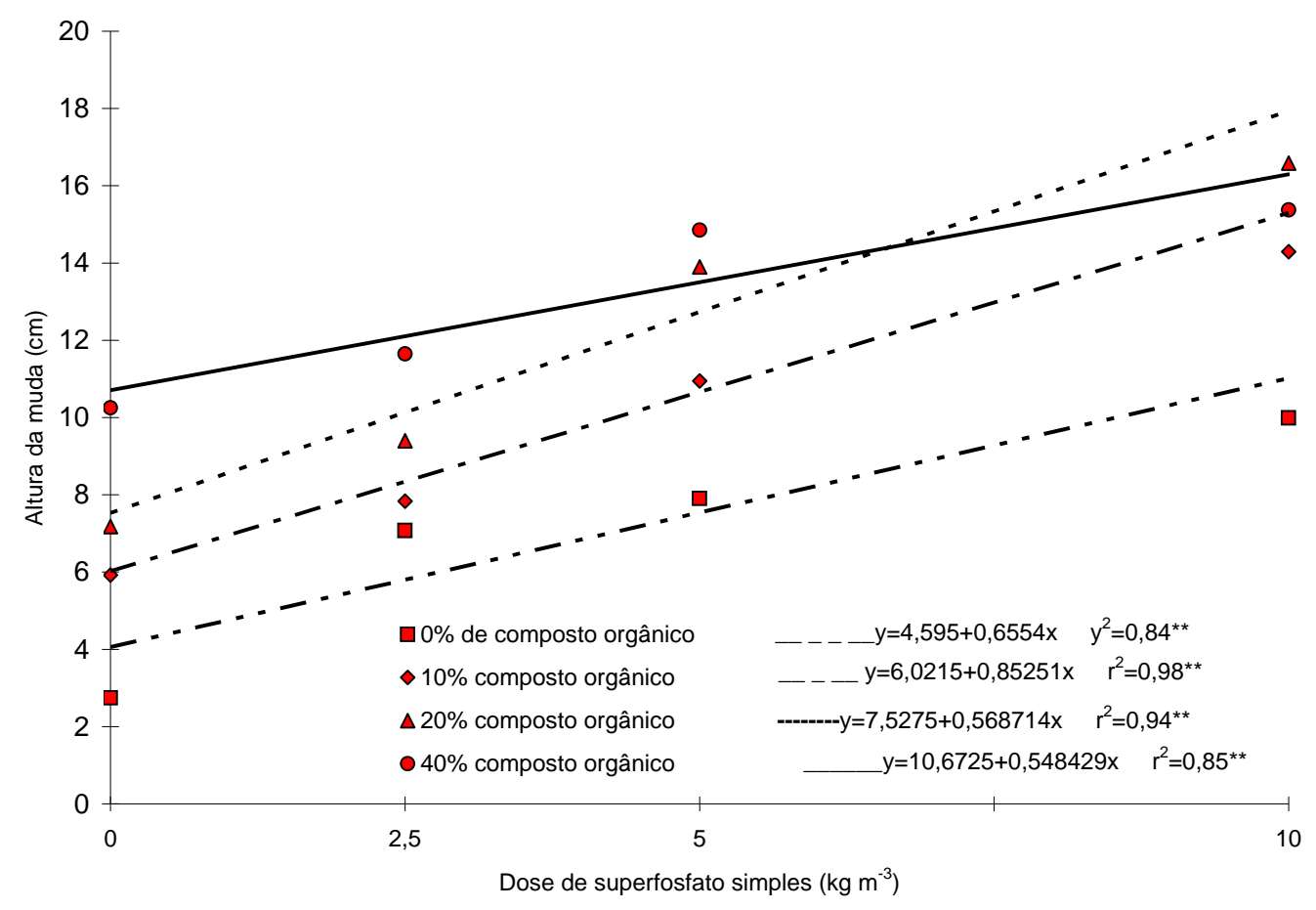

FIGURA 1 - Altura de mudas de mamoeiro 'Formosa' como variável da aplicação de superfosfato simples em diferentes doses de composto orgânico. Lavras, MG, 2004.

Ciênc. agrotec., Lavras, v. 30, n. 5, p. 861-868, set./out., 2006 


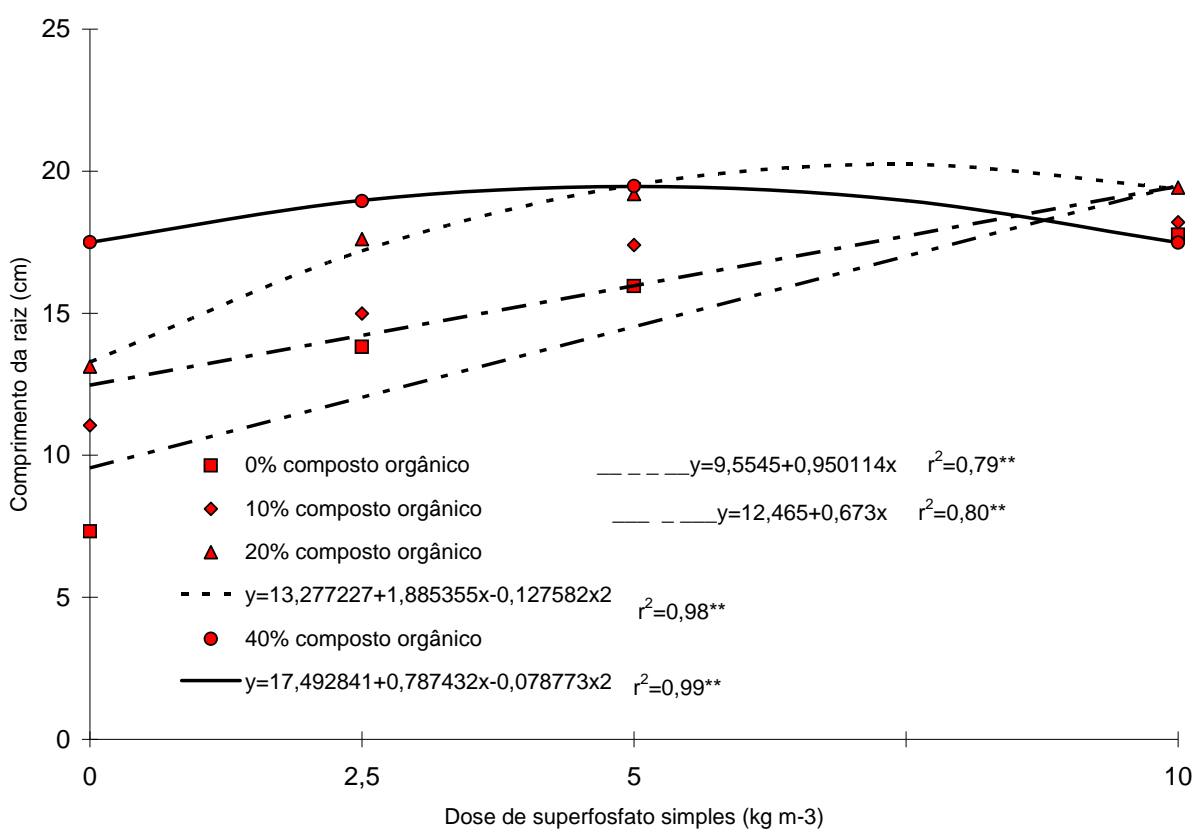

FIGURA 2 - Comprimento da raiz de mudas de mamoeiro 'Formosa' como variável da aplicação de superfosfato simples em diferentes doses de composto orgânico. Lavras, MG, 2004.

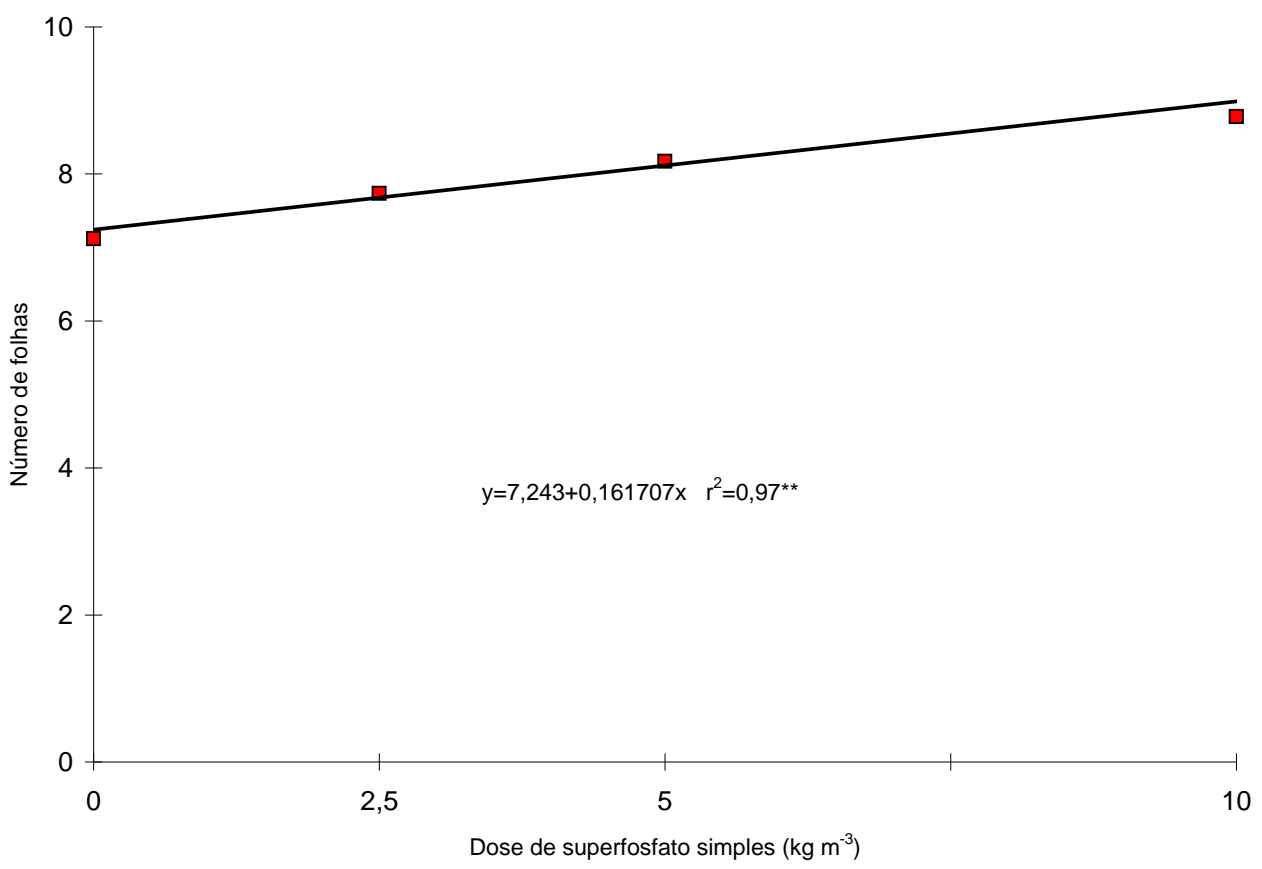

FIGURA 3 - Número de folhas de mudas de mamoeiro 'Formosa' como variável da aplicação de superfosfato simples. Lavras, MG, 2004.

Ciênc. agrotec., Lavras, v. 30, n. 5, p. 861-868, set./out., 2006 


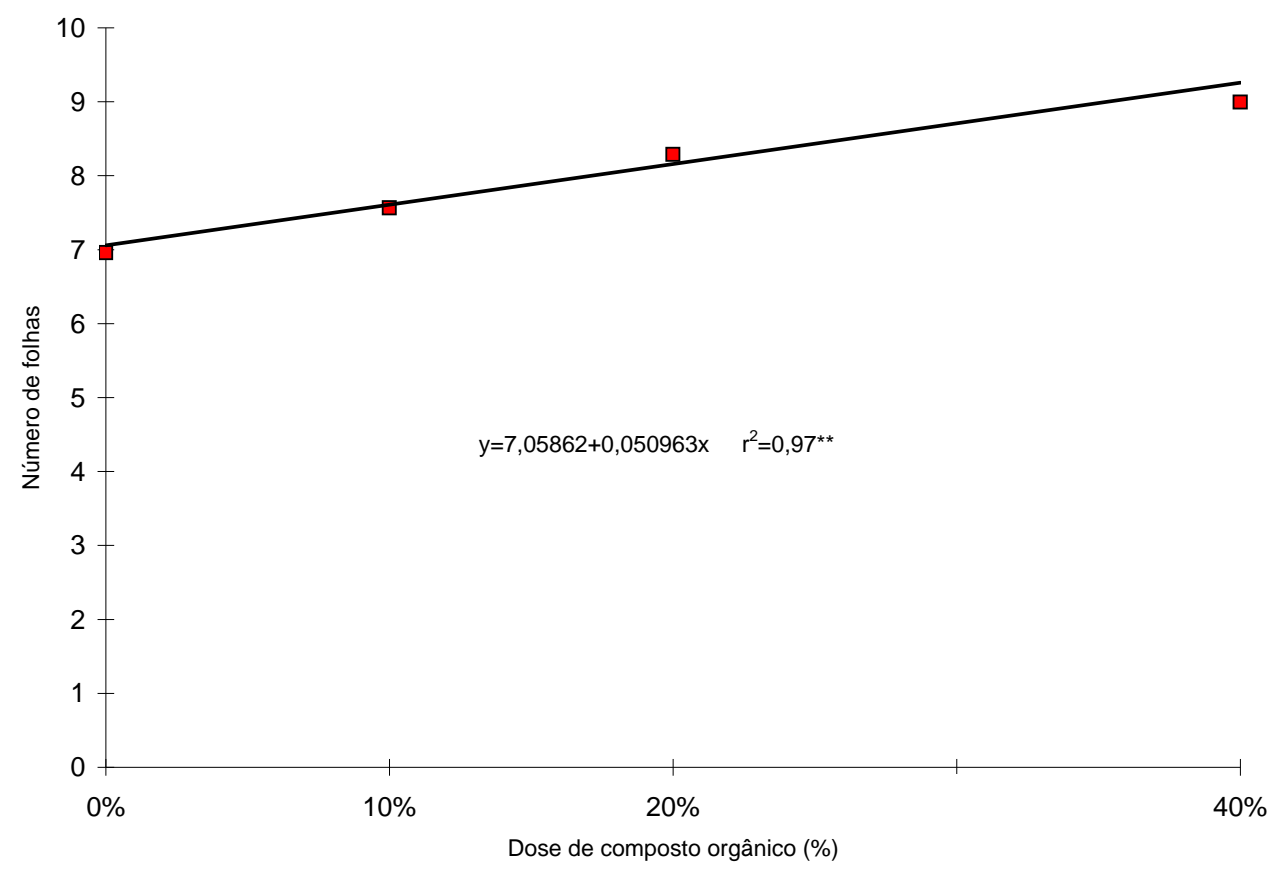

FIGURA 4 - Número de folhas de mudas de mamoeiro 'Formosa' como variável da aplicação de composto orgânico. Lavras, MG, 2004.

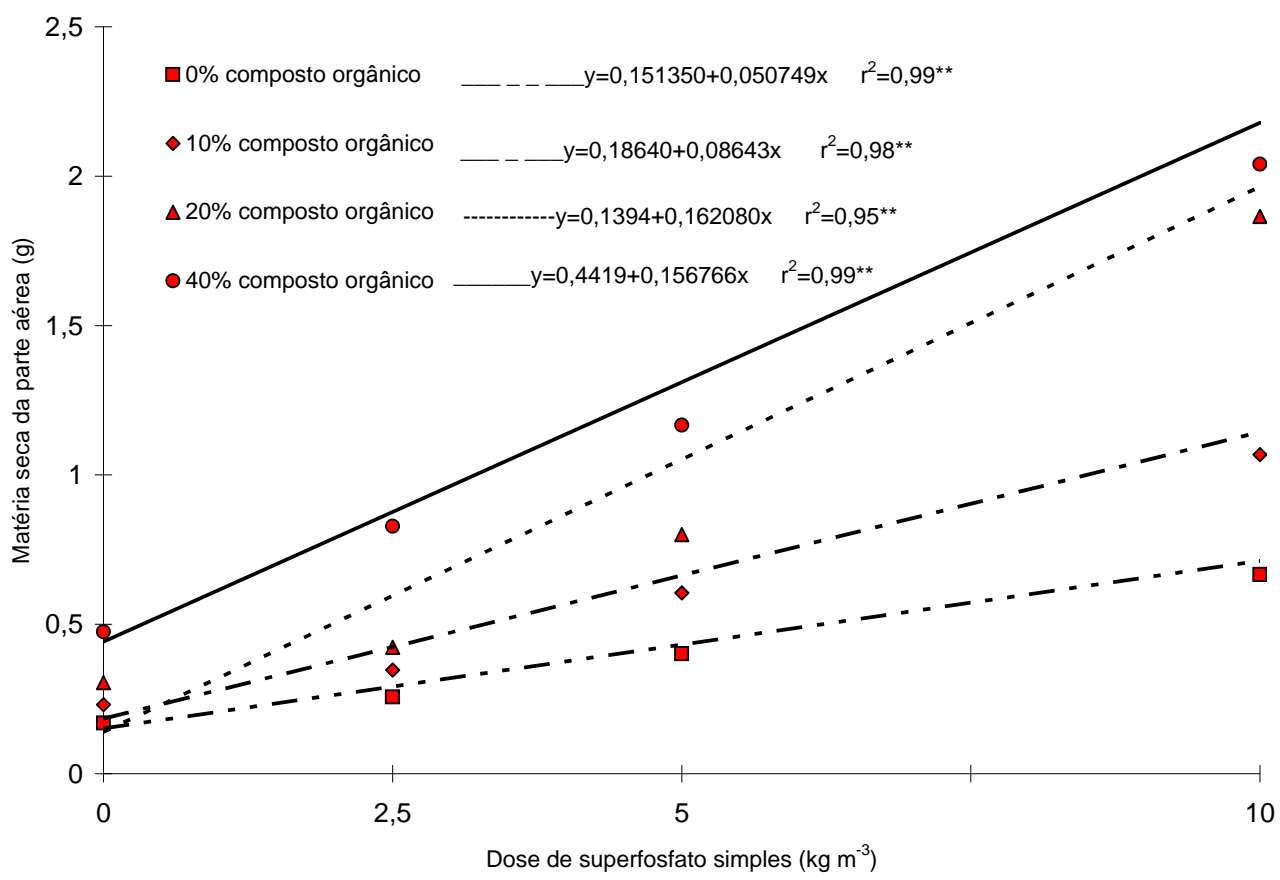

FIGURA 5 - Matéria seca da parte aérea de mudas de mamoeiro 'Formosa' como variável da aplicação de superfosfato simples em diferentes doses de composto orgânico. Lavras, MG, 2004.

Ciênc. agrotec., Lavras, v. 30, n. 5, p. 861-868, set./out., 2006 


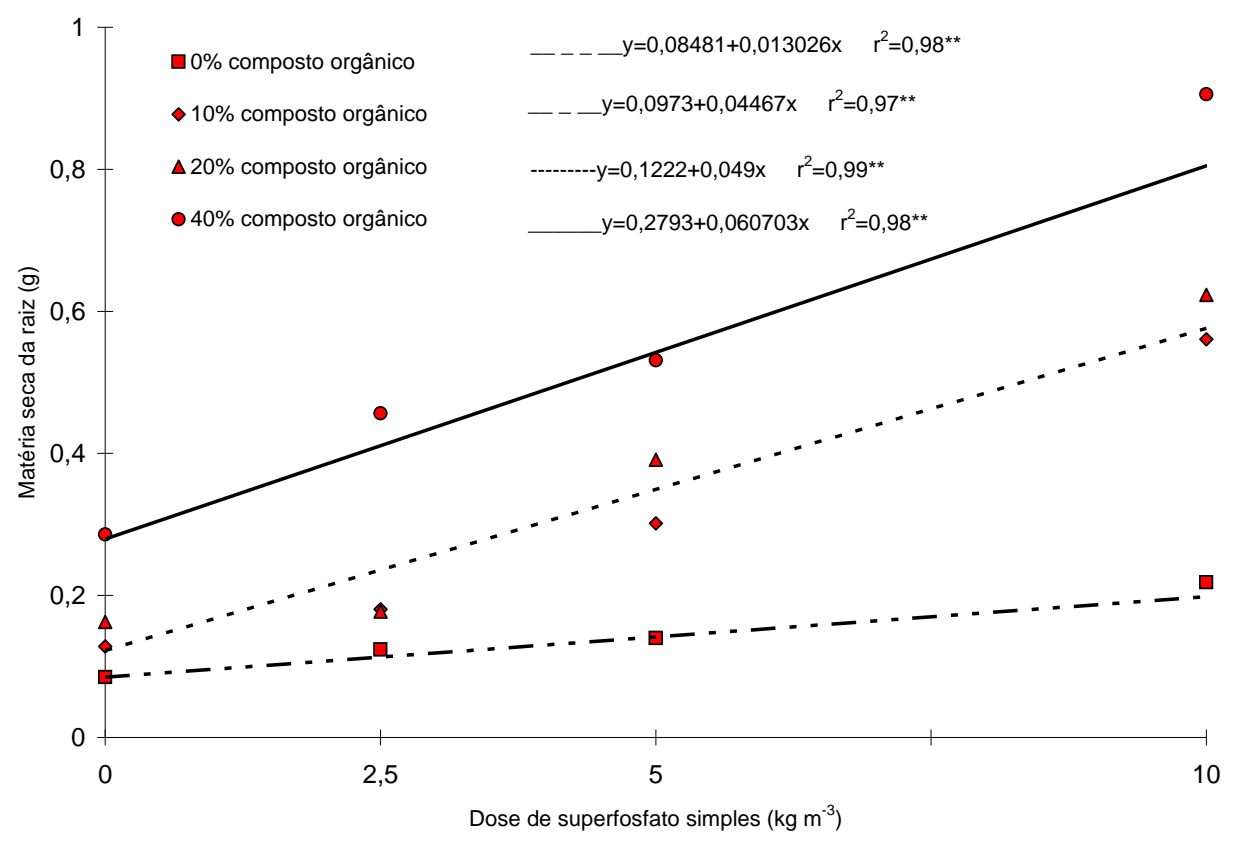

FIGURA 6 - Matéria seca da raiz de mudas de mamoeiro 'Formosa' como variável da aplicação de superfosfato simples em diferentes doses de composto orgânico. Lavras, MG, 2004.

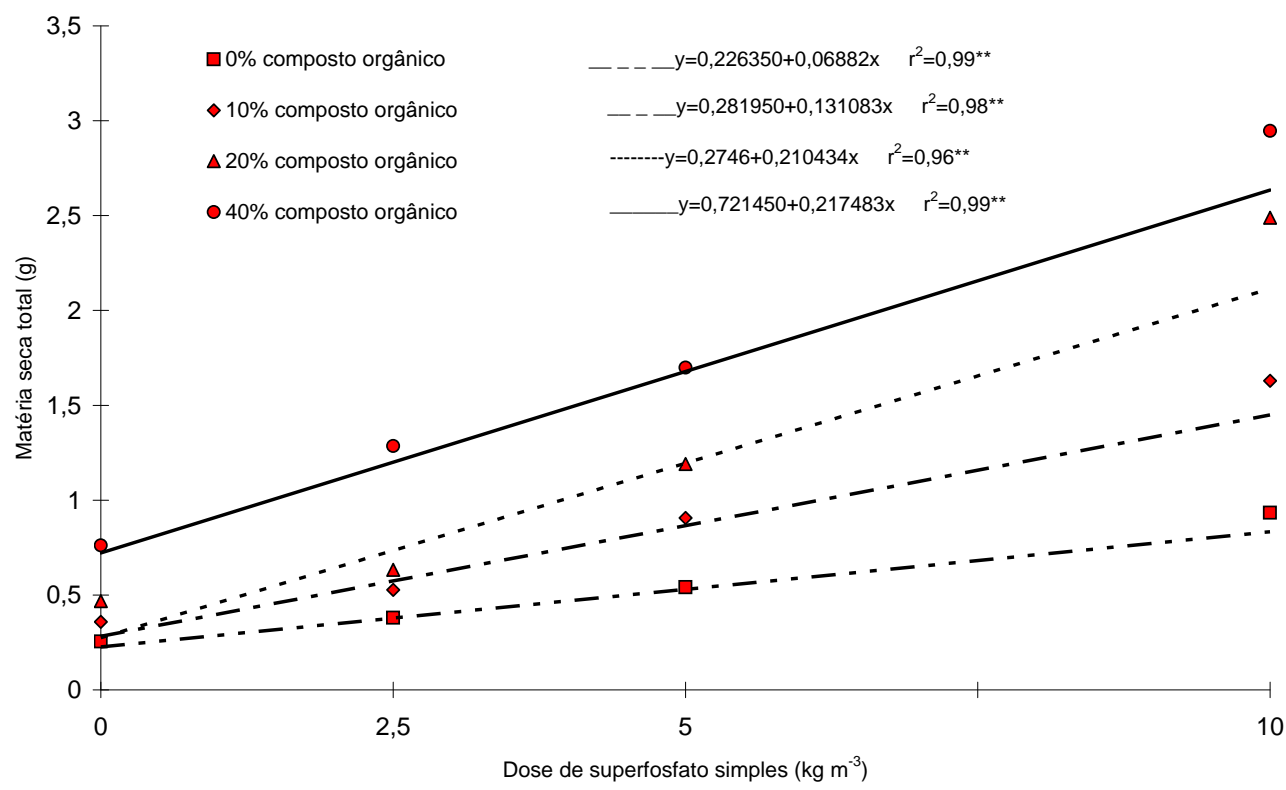

FIGURA 7 - Matéria seca total de mudas de mamoeiro 'Formosa' como variável da aplicação de superfosfato simples em diferentes doses de composto orgânico. Lavras, MG, 2004.

Ciênc. agrotec., Lavras, v. 30, n. 5, p. 861-868, set./out., 2006 
Mistura de terra com esterco e/ou adubos minerais produziram mudas de mamoeiro mais vigorosas avaliadas por meio da altura, do comprimento das raízes e da massa da matéria seca total (FERNANDES et al., 2002). Já Oliveira et al. (2002) concluíram que a utilização do esterco bovino foi melhor quando associado ao húmus de minhoca, para a altura e diâmetro; e para o número de folhas, associado ao solo em muda de mamoeiro. Mendonça et al. (2003) recomendam substratos contendo esterco de curral curtido, carvão vegetal, solo e areia na proporção de 2:1:1:1 em volume como sendo uma boa alternativa para formação de mudas de mamoeiro.

\section{CONCLUSÕES}

A utilização do superfosfato simples na dose de 10 $\mathrm{kg} \mathrm{m}^{-3} \mathrm{em}$ substrato para formação da muda garantiu melhor qualidade na formação de mudas de mamoeiro 'Formosa'.

O composto orgânico em percentuais de $40 \%$ no substrato mostrou ser uma alternativa de matéria orgânica viável, para formação de mudas de mamoeiro 'Formosa'.

\section{REFERÊNCIAS BIBLIOGRÁFICAS}

AGRIANUAL. Anuário estatístico do Brasil. São Paulo: FNP Consultoria \& Comércio, 2004. 536 p.

CARMELLO, Q. A. de C. Nutrição e adubação de mudas hortícolas. In: MINAMI, Q. (Ed.). Produção de mudas de alta qualidade em horticultura. São Paulo: T. A. Queiroz, 1995. p. 7-27.

FERNANDES, F. M.; CANASIN, R. C. F. S.; CORRÊA, L. de S. Adubação orgânica e/ou mineral no crescimento de mudas de mamoeiro (Carica papaya L.). In: CONGRESSO BRASILEIRO DE FRUTICULTURA, 17., 2002, Belém. Anais... Belém: SBF, 2002. CD-ROM.

FERREIRA, D. F. Análise estatística por meio do SISVAR (Sistema para Análise de Variância) para Windows versão 4.0. In: REUNIÃO ANUAL DA REGIÃO BRASILEIRA DA SOCIEDADE INTERNACIONAL DE BIOMETRIA, 45., 2000, São Carlos. Anais... São Carlos: UFSCar, 2000. p. 255-258.

GOMES, F. P. Curso de estatística experimental. 14. ed. Piracicaba: USP, 2000. 477 p.

LIMA, M. L. de F. N. Efeito da composição do substrato na formação de mudas de mamoeiro cv. Sunrise Solo. In: CONGRESSO BRASILEIRO DE FRUTICULTURA, 14., 1996, Curitiba. Anais... Curitiba: IAPAR, 1996. p. 295.
MENDONÇA, V.; ARAÚJO NETO, S. E. de; RAMOS, J. D.; PIO, R.; GONTIJO, T. C. A. Diferentes substratos e recipientes na formação de mudas de mamoeiro 'Sunrise Solo'. Revista Brasileira de Fruticultura, Jaboticabal, v. 25, n. 1, p. 127-130, abr. 2003.

OLIVEIRA, A. M. G.; FARIAS, A. R. N.; SANTOS FILHO, H. P.; OLIVEIRA, J. R. P.; DANTAS, J. L. L.; SANTOS, L. B. dos; OLIVEIRA, M. de A.; SOUZA JUNIOR, M. T.; SILVA, M. J.; ALMEIDA, O. A. de; NICKEL, O.; MEDINA, V. M.; CORDEIRO, Z. J. M. Mamão para exportação: aspectos técnicos da produção. Brasília, DF: Embrapa-SPI, 1994. 52 p. (FRUPEX. Publicações técnicas, 9).

OLIVEIRA, S. J. C.; LEÃO, A. C.; FERREIRA, E. G.; SILVA, P. O. da; MARINHO, F. J. L. QUEIROZ, M. F. de. Efeito de três fontes de matéria orgânica na produção de mamoeiro. In: CONGRESSO BRASILEIRO DE FRUTICULTURA, 17. 2002, Belém. Anais... Belém: SBF, 2002. CD-ROM.

PONTES, H. M. Substratos para a produção de mudas de mamoeiro (Carica papaya L.) na Amazônia Ocidental. Revista da Universidade do Amazonas, Série Ciências Agrárias, Manaus, v. 1, n. 1, p. 57-64, 1991.

ROCHA, A. C. Efeito da matéria orgânica e do superfosfato simples na formação de mudas do mamoeiro (Carica papaya L. cv. Solo). 1987. 52 f. Dissertação (Mestrado em Fitotecnia) - Escola Superior de Agricultura de Lavras, Lavras, 1987.

SIMÃO, S. Tratado de fruticultura. Piracicaba: FEALQ, 1998. $760 \mathrm{p}$.

SOARES, N. B. Mamão Carica papaya L. In: FAHL, J. I.; CAMARGO, M. B. P.; PIZZINATTO, M. A.; BETTI, J. A.; MELO, A. M. T. de; MARIA, I. C. de; FURLANI, A. M. C. (Eds.). Instruções agrícolas para as principais culturas econômicas. Campinas: IAC, 1998. p. 137-138. (Boletim, 200).

TRINDADE, A. V. Uso de esterco no desenvolvimento de mudas de mamoeiro colonizados com fungos micorrízicos. Pesquisa Agropecuária Brasileira, Brasília, v. 35, n. 7, p. 1389-1394, 2000.

YEAGER, T. H.; WRIGHT, R. D. Response of IIex crenat Thunb. cv. Helleri to superphosphat-incorporated pine bark. Hortscience, Alexandria, v. 19, n. 7, p. 823-826, July 1984. 